\title{
COMMENTARY
}

\section{What is the NHS for?}

Asthana and Gibson challenge 'the conventional wisdom of inverse care'. Analysing primary care data from England, they show that the mismatch between need and resource, resulting in inequitable access to health care, applies as much to the health needs of older populations as deprived populations, and is especially the case in populations that are both older and deprived. This is an important and, in places, a contentious paper, raising issues that may help to clarify what is meant by inverse care and how it should be addressed.

Readers with long memories may be reminded of the Jarman deprivation score, which was pragmatically constructed to reflect what makes GPs busy, and thus included a measure of the numbers of older patients served. Concern about workload is also familiar to the GP negotiators of the British Medical Association whose traditional position has been that GPs should be similarly resourced and rewarded for being busy. However, there is more to the NHS than paying doctors, and keeping doctors busy is no guarantee of social justice.

Asthana and Gibson observe that while almost everyone seems familiar with the 'inverse care law', there is little precise understanding of what it is and how it should be addressed. Tudor Hart's original paper contained few data and was principally concerned with the effects of market forces. ${ }^{2}$ More recent discussion has begun to tease out different definitions of access, according to structure, process, and outcome ${ }^{3}$ and taking into account the increasing ability of health care to increase longevity. ${ }^{4}$ By distinguishing 'public health and other preventive efforts' from 'curative care', Asthana and Gibson appear to undervalue what can be achieved by the NHS, reversing risks and preventing complications in large numbers of people, as first demonstrated by Julian Tudor Hart. ${ }^{5}$

The desk-based analyses presented in the paper are similar to many in the last decade, trying to rationalise the distribution of NHS resources according to need. However, a clear picture remains elusive. Not only are general practice populations not geographical, but their social heterogeneity, both within practices, and between practices within geographical areas, makes it difficult to focus on areas of the NHS where needs are greatest. Studies based on $100 \%$ of practices are also hampered by the limited availability of quality data. For example, although the Quality and Outcomes Framework (QOF) provides prevalence and activity data for almost every practice in the country, the prevalence data are not broken down by age and the clinical activity data cover only the most measurable aspects of primary care.

As Asthana and Gibson report, QOF data do allow some estimation of the multiple morbidity associated with ageing, in which individual patients tend to have several clinical diagnoses. Much less information is available to desk epidemiologists on the multiple morbidity typically associated with deprivation, which is made up of the number, severity, and complexity of health and social problems within families.

In the absence of epidemiological measures of need, NHS resource distribution formulae have sometimes used measures of activity as a proxy for need, which works well for reactive aspects of care (for example, routine consultations, out-of-hours care, and emergency hospital admissions) where needs are largely expressed as demands, but much less well for non-acute aspects of care (such as preventive care and access to specialist services) where unmet need simply results in a data void. Unfortunately, these are the aspects of care whereby the NHS is most effective in improving health.

Unmet need is a real phenomenon in frontline primary care. In a recent study of over 3000 general practice consultations, ${ }^{6}$ Mercer showed that consultations are shorter in deprived areas than in affluent areas, that patients with comorbidity, including a mental health problems, are less likely to have a long consultation, and that they are less likely to report being satisfied or enabled as a result of the consultation. GPs in deprived areas also report being under greater stress. ${ }^{6}$ For frontline staff, it is not a question of conforming to a 'widely held' view that practices in deprived areas are under-resourced relative to need. The time constraints, and their cultural sequelae are all too real. ${ }^{7}$

Asthana and Gibson observe that the social gradients associated with deprivation are steeper using data collected externally from general practice, such as mortality and hospital admissions, than they are using clinical data collected from within general practice. Part of the explanation may be the inability of practices in deprived areas, as a result of the historical distribution of GPs and their staff, to generate evidence of need, via activity.

Another explanation, which is the crux of Asthana and Gibson's paper, is the extent to which these relationships are obscured by the more widespread and dominant effect on morbidity and workload of age. ${ }^{1}$ For example, although premature cardiovascular disease (CVD) is steeply socially patterned, the effects of recent trends in incidence and survival, for which the NHS can claim some credit,, have been to increase the prevalence of older people with angina and heart failure. Although CVD keeps all primary care teams busy, age profiles and case-mixes are socially patterned.

The evidence and arguments that the NHS can improve population health via the delivery of effective interventions, and widen health inequalities via the inequitable delivery of these interventions, is based chiefly on measures that reduce the severity and slow the progression of established conditions and risks. ${ }^{10}$ As a strategy it must be targeted at older populations. Asthana and Gibson show that as the population profiles in many deprived areas are relatively young, strategies that target deprivation per se may take a very long time to improve health and narrow inequalities.

Whether general practices serving older people in deprived areas can rise to the challenge depends on much more than a simple injection of resources. Just as hyperalimentation is not a treatment for chronic under-nutrition, the re-invigoration of general practice in deprived areas cannot happen overnight. Nevertheless, insofar as this approach to health improvement depends on contact, continuity, coordination, flexibility and, above all, productive relationships, ${ }^{11}$ general practice is surely the only policy option.

If the NHS determines to narrow differences in life expectancy, as it is now able to do via the more equitable delivery of effective interventions, ${ }^{12}$ it is axiomatic that this will involve discrimination between those with and without longevity. In the same way that it is more expensive and difficult for epidemiologists to obtain high response rates for studies in deprived areas, population 
approaches to clinical care are likely to be more expensive in deprived areas. ${ }^{3}$ Whether society is prepared to pay for this will depend, among other things, on its tolerance of large differences in life expectancy.

The main value of Asthana and Gibson's paper is that it highlights the contrast and potential conflict between two overlapping but different interpretations of the inverse care law, in which 'good medical care' is defined either as access based on need, favouring older people, or the equitable and successful delivery of effective interventions that improve health and longevity. Ultimately, this is a political rather than a statistical issue, but statistics can help politicians address the question 'What is the NHS for?'.

\section{Graham CM Watt,}

Professor of General Practice, General Practice and Primary Care, Division of Community-based Sciences, University of Glasgow, 1 Horselethill Road, Glasgow G11 5AW. Email: gcmw1j@clinmed.gla.ac.uk

\section{REFERENCE}

1. Asthana S, Gibson A. Deprivation, demography, and the distribution of general practice: challenging the conventional wisdom of inverse care. Br J Gen Pract 2008 ; 58: 719-727.

2. Hart JT. The inverse care law. Lancet 1971; 1(7696): 405-412.

3. Watt G. The inverse care law today. Lancet 2002; 360(9328): 252-254.

4. Bunker JP. Medicine matters after all: measuring the benefits of medical care, a healthy lifestyle and a just social environment. London: Nuffield Trust for Research and Policy Studies in Health Services, 2001.

5. Hart JT, Thomas C, Gibbons B, et al. Twenty-five years of audited screening in a socially deprived community. BMJ 1991; 302: 1509-1513.

6. Mercer SW, Watt GCM. The inverse care law: clinical primary care encounters in deprived and affluent areas of Scotland. Ann Fam Med 2007; 5(6): 503-510.

7. Conlon M, Brinksman S, Manley V, et al. The NHS at 60. Br J Gen Pract 2008; 58: 648.

8. Unal B, Critchley JA, Capewell S. Modelling the decline in coronary heart disease deaths in England and Wales, 1981-2000: comparing contributions from primary prevention and secondary prevention. BMJ 2005; 331: 614 .

9. Lampe FC, Morris RW, Walker M, et al. Trends in rats of different forms of diagnosed coronary heart disease, 1978 to 2000: prospective, population-based study of British men. BMJ 2005; 330: 1046-1049.

10. Starfield B. Contributions of evidence to the struggle towards equity. The John Fry Fellowship Lecture. London: Nuffield Trust for Research and Policy Studies in Health Services, 2004.

11. Hart JT. The political economy of health care: a clinical perspective. Bristol: Policy Press, 2006.

12. Cutler DM Meara E. Changes in the age distribution of mortality over the 20th century. Working Paper 8556. Cambridge MA: National Bureau of Economic Research, 2001.

DOI: 10.3399/bjgp08X342381

15. Asthana S, Gibson A. healthcare equity, health equity and resource allocation: towards a normative approach to achieving the core principles of the NHS. Radical Statistics 2008; 96: 6-26.

16. Galbraith J. The fantasy of fair funding of primary care trusts. Radical Statistics 2008; 96: 27-37.

17. Stone M, Galbraith J. How not to fund hospital and community health services in England. J R Stat Soc (Ser A) 2006; 169(1): 143-164.

18. Asthana S, Gibson A, Moon G, et al. The demographic and social class basis of inequalities in morbidity: a comparison. J Epidemiol Community Health 2004; 58(4): 303-307.

19. Seshamani M. Gray AM. A longitudinal study of the effects of age and time to death on hospital costs. J Health Econ 2004; 23(2): 217-235.

20. McLean G, Sutton M, Guthrie B. Deprivation and quality of primary care services: evidence for persistence of the inverse care law from the UK Quality and Outcomes Framework. J Epidemiol Community Health 2006; 60(11): 917-922.

21. Yorkshire and Humber Pubic Health Authority. PBS phase 3 diabetes population prevalence model.

http://www.yhpho.org.uk/PBS_diabetes.aspx (accessed 4 Sep 2008).

22. Sutton M, Gravelle H, Morris S, et al. Allocation of resources to English areas: individual and small area determinants of morbidity and use of healthcare resources. Report to the Department of Health. Edinburgh: Information and Statistics Division, 2002.

23. Morris $\mathrm{S}$, Sutton $\mathrm{M}$, Gravelle $\mathrm{H}$. Inequity and inequality in the use of health care in England: an empirical investigation. Soc Sci Med 2005; 60(6): 1251-1266.

24. Dixon-Woods M, Kirk D, Agarwal S, et al. Vulnerable groups and access to health care: a critical interpretive review. London: NCCSDO, 2005.

25. Beale N, Talyor G, Straker-Cook D, et al. Council tax valuation band of patient residence and clinical contacts in a general practice. $\mathrm{Br} \mathrm{J} \mathrm{Gen}$ Pract 2005; 55(510): 32-56.

26. Ashworth M, Armstrong D. The relationship between general practice characteristics and quality of care: a national survey of quality indicators used in the UK Quality and Outcomes Framework, 2004-5. BMC Fam Pract 2006; 7: 68.

27. Ashworth M, Seed P, Armstrong D, et al. The relationship between social deprivation and the quality of primary care: a national survey using indicators from the UK Quality and Outcomes Framework. Br J Gen Pract 2007; 57(539): 441-448.

28. Saxena S, Car J, Eldred D, et al. Practice size, caseload, deprivation and quality of care of patients with coronary heart disease, hypertension and stroke in primary care: national cross-sectional study. BMC Health Serv Res 2007; 7: 96.

29. Millet C, Car J, Eldred D, et al. Diabetes prevalence, process of care and outcomes in relation to practice size, caseload and deprivation: national cross-sectional study in primary care. J R Soc Med 2007; 100(6): 275-283.

30. Gulliford MC, Ashworth M, Robotham D, Mohiddin A. Achievement of metabolic targets for diabetes by English primary care practices under a new system of incentives. Diabet Med 2007; 24(5): 505-511.

31. Strong M, Maheswaran R, Radford J. Socioeconomic deprivation, coronary heart disease prevalence and quality of care: a practice-level analysis in Rotherham using data from the new UK general practitioner Quality and Outcomes Framework. J Public Health 2006; 28(1):39-42.

32. Ashworth M, Lloyd D, Smith RS, et al. Social deprivation and statin prescribing: a cross-sectional analysis using data from the new UK general practitioner Quality and Outcomes Framework. J Public Health 2007; 29(1): 40-47.

33. Edwards A, Pill R. Patterns of help-seeking behaviour for toddlers from two contrasting socioeconomic groups: new evidence on a neglected topic. Fam Pract 1996; 13(4): 377-381.

34. Alberts JF, Sanderman R, Gerstenbluth I, van den Heuvel WJ Sociocultural variations in help-seeking behavior for everyday symptoms and chronic disorders. Health Policy 1998; 44(1): 57-72.

35. Saxena S, Majeed A, Jones M. Socioeconomic differences in childhood consultation rates in general practice in England and Wales: prospective cohort study. BMJ 1999; 3189(7184): 642-646.

36. Stirling AM, Wilson P, McConnachie A. Deprivation, psychological stress and consultation length in general practice. Br J Gen Pract 2001; 51(467): 456-460.

37. Mercer SW, Watt GC. The inverse care law: clinical primary care encounters in deprived and affluent areas of Scotland. Ann Fam Med 2007; 5(6): 503-510.

38. Department of Health. National Service Framework for older people. London: Department of Health: 2001.

39. Professor Lord Darzi. High quality care for all: NHS Next Stage Review final report. London: Department of Health, 2008. http://www.dh.gov.uk/en/Publicationsandstatistics/Publications/Public ationsPolicyAndGuidance/DH_085825 (accessed 5 Sep 2008).

40. Graham H. Social determinants and their unequal distribution: clarifying policy understandings. Milbank Q 2004; 82(1): 101-124. 